Journal

Hydrology

www.elsevier.com/locate/jhydrol

\title{
Two-dimensional kinematic wave model of overland-flow
}

\author{
Q.Q. Liu ${ }^{\mathrm{a}}$, L. Chen ${ }^{\mathrm{a}}$, J.C. Li ${ }^{\mathrm{a}}$, V.P. Singh ${ }^{\mathrm{b}, *}$ \\ ${ }^{a}$ Institute of Mechanics, Chinese Academy of Sciences, Beijing 100080, China \\ ${ }^{\mathrm{b}}$ Department of Civil and Environmental Engineering, Louisiana State University, Baton Rouge, LA 70803-6405, USA
}

Received 26 June 2002; revised 10 November 2003; accepted 10 December 2003

\begin{abstract}
A two-dimensional kinematic wave model was developed for simulating runoff generation and flow concentration on an experimental infiltrating hillslope receiving artificial rainfall. Experimental observations on runoff generation and flow concentration on irregular hillslopes showed that the topography of the slope surface controlled the direction and flow lines of overland flow. The model-simulated results satisfactorily compared with experimental observations. The erosive ability of the concentrated flow was found to mainly depend on the ratio of the width and depth of confluent grooves.
\end{abstract}

(C) 2004 Elsevier B.V. All rights reserved.

Keywords: Flow concentration route; Infiltration; Hillslope; Kinematic wave theory; Numerical simulation; Overland flow; Runoff generation; 2D flow model

\section{Introduction}

When the rainfall intensity exceeds soil infiltration, water begins to accumulate on the surface and then it flows down the slope under gravity as overland flow. A hillslope with a simple configuration can generally be simplified as a one-dimensional (1D) slope with smooth and uniform surface. The runoff generation process on this kind of hillslope can be simulated by the average soil infiltration and 1D kinematic wave theory (Lighthill and Witham, 1955; Woolhiser and Ligget, 1967; Freeze, 1978; Cundy and Tento, 1985; Singh, 1996; Tang and Chen, 1997; Chen et al., 2001a,b; Li et al., 2003). However, an actual hillslope is generally not smooth and exhibits local irregularities, especially grooves. While the surface landform

\footnotetext{
* Corresponding author. Fax: +1-225-338-8652.

E-mail address: cesing@1su.edu (V.P. Singh).
}

of a hillslope appears undulating in the transverse direction, the overland flow caused by rainfall flows into low-lying areas, and forms concentration flow routes which constitute the main cause of rill formation. Simulation of these concentration routes on the surface landform of hillslopes is important for prediction of runoff generation and soil erosion. This is particularly true in the loess plateau areas of China where the geomorphology is fragmented ( $\mathrm{Li}$ et al., 2003).

The process of runoff generation on a hillslope with a complex topography should be simulated such that the process of flow concentration is adequately represented. Clearly, a 1D model is inadequate to properly simulate the direction of overland flow therefore, a 2D model is needed. Govindaraju et al. (1992) presented a simplified 2D diffusion wave model for overland flow and compared the model 
results with observations. Tayfur et al. (1993) evaluated the applicability of the St Venant equations for $2 \mathrm{D}$ overland flow over rough infiltrating surfaces. Since the flow profile is perceived to be thin, the microtopography is replaced by a smoother surface for computational purposes. The model results were in satisfactory agreement with observations on experimental hillslopes. Tayfur and Kavvas (1998) derived areally averaged kinematic wave equations for overland flow at the hillslope scale. Comparison of the results from these equations with observed data was satisfactory and that with those of other models indicated the superiority of these equations. Tayfur (2001) modeled the 2D erosion process over infiltrating surfaces. Overland flow was modeled using kinematic wave equations. The soil erodibility coefficient and the shear stress exponent exercised a pronounced influence on sediment discharge.

Scoging (1992) developed a distributed mathematical model of hillslope overland flow. This model employed a flowline vector for determining the direction of flow by calculating the heights of the four angular points of computational elements or cells. The flowline vector was represented as originating from the highest corners of a cell, with its magnitude and direction determined from the relative heights of four corners of the cell. The side intersecting the vector was considered the outlet of the cell for flow, with the assumption that all the water of the element flowed out from this side. Thus, every element conveyed water to its adjacent element; at the same time every element could receive flow from the four adjacent elements. Using a 1D difference equation obtained between the downstream cell and its several upstream cells, the process of runoff and the concentrated flow routes was described for the whole area. In this manner, the pattern of concentrated flow approximated the real pattern.

The objective of this study is to develop a 2D kinematic wave model for simulating non-uniform overland flow and its flowline concentration on hillslopes with irregular surfaces. The model simulates flow concentration and confluent characteristics of overland flow. The model would also accommodate the case when the water might flow out from two lower side boundaries but one side boundary.

\section{Overland flow model}

\subsection{D Experiments}

In order to develop an understanding of the processes of runoff generation and soil erosion on a slope, a series of 1D experiments were conducted on a plot (or soil flume) with artificial rainfall at the Northwestern Institute of Water and Soil Conservation, Chinese Academy of Science. The test-plot was a $320 \mathrm{~cm}$ long, $100 \mathrm{~cm}$ wide, and $30 \mathrm{~cm}$ deep wooden-box with holes at the bottom. The holes at the bottom prevented water accumulation in the bottom of box when rainfall time was too long. The slope or the gradient of the test-plot was adjustable and was varied. Rainfall was simulated by the dropformer type rainfall simulator of artificial precipitation in which raindrops were formed at $16 \mathrm{~m}$ above from the surface of test-plot and the falling raindrops attained a fixed speed near the surface. The rainfall intensity was adjusted in the range of $15 \sim 200 \mathrm{~mm} / \mathrm{h}$. The soil used in the experiment was the local loess of Yangling in the Shanxi province of China. The soil was packed to a $25 \mathrm{~cm}$ thickness with plane surface in the wooden-box. Before and after the experiment, the bulk density, moisture content and porosity of the soil were measured by using a ring sampler (see Table 1).

The runoff discharge, runoff volume, and sediment concentration were measured at the outlet of the testplot for different rainfall intensities and slopes (gradients). To determine the runoff discharge and sediment concentration, runoff samples containing the sediment were collected at the outlet of test-plot. Samples of approximately $300 \mathrm{ml}$ were obtained using beakers. The flow discharges were obtained by dividing the sample volume by the collection time, while the sediment concentrations in each of these samples were determined later by weighting on the scale after baking. At the same time, all of the runoff at the outlet was collected, which was continuously measured in a cylindrical container to determine the runoff volume. Then, the accumulated erosion quantity was determined from the measurements of runoff discharge, sediment concentration, and runoff volume as well. Pertinent characteristics of the five experiments (cases) conducted for different rainfall events are given in Table 1. 
Table 1

Pertinent characteristics of five experiments (cases)

\begin{tabular}{|c|c|c|}
\hline Case & Characteristics & \\
\hline \multirow[t]{4}{*}{1} & Rainfall intensity: $3.16 \mathrm{~mm} / \mathrm{min}$, & $\begin{array}{l}\text { Inclination angle of slope: } \\
15^{\circ}\end{array}$ \\
\hline & Initial water content: $6.97 \%$ & $\begin{array}{l}\text { Water content after test: } \\
27.17 \%\end{array}$ \\
\hline & $\begin{array}{l}\text { Initial soil bulk density: } \\
1.40 \mathrm{~g} / \mathrm{cm}^{3}\end{array}$ & $\begin{array}{l}\text { Soil bulk density after } \\
\text { test: } 1.69 \mathrm{~g} / \mathrm{cm}^{3}\end{array}$ \\
\hline & Water temperature: $24{ }^{\circ} \mathrm{C}$ & $\begin{array}{l}\text { Time in which rill } \\
\text { occurs: } 13^{\prime} 30^{\prime \prime}\end{array}$ \\
\hline \multirow[t]{3}{*}{2} & Rainfall intensity: $1.0 \mathrm{~mm} / \mathrm{min}$ & $\begin{array}{l}\text { Inclination angle of slope: } \\
20^{\circ}\end{array}$ \\
\hline & Initial water content: $8.6 \%$ & $\begin{array}{l}\text { Initial soil bulk density: } \\
1.2 \mathrm{~g} / \mathrm{cm}^{3}\end{array}$ \\
\hline & Water temperature: $15^{\circ} \mathrm{C}$ & $\begin{array}{l}\text { Time in which rill } \\
\text { occurs: } 61^{\prime} 00^{\prime \prime}\end{array}$ \\
\hline \multirow[t]{3}{*}{3} & Rainfall intensity: $1.34 \mathrm{~mm} / \mathrm{min}$ & $\begin{array}{l}\text { Inclination angle of slope: } \\
20^{\circ}\end{array}$ \\
\hline & Initial water content: $8.6 \%$ & $\begin{array}{l}\text { Initial soil bulk density: } \\
1.2 \mathrm{~g} / \mathrm{cm}^{3}\end{array}$ \\
\hline & Water temperature: $12{ }^{\circ} \mathrm{C}$ & $\begin{array}{l}\text { Time in which rill } \\
\text { occurs: } 35^{\prime} 00^{\prime \prime}\end{array}$ \\
\hline \multirow[t]{4}{*}{4} & Rainfall intensity: $2.62 \mathrm{~mm} / \mathrm{min}$ & $\begin{array}{l}\text { Inclination angle of slope: } \\
25^{\circ}\end{array}$ \\
\hline & Initial water content: $25.04 \%$ & $\begin{array}{l}\text { Water content after test: } \\
32.52 \%\end{array}$ \\
\hline & $\begin{array}{l}\text { Initial soil bulk density: } \\
1.63 \mathrm{~g} / \mathrm{cm}^{3}\end{array}$ & $\begin{array}{l}\text { Soil bulk density after } \\
\text { test: } 1.68 \mathrm{~g} / \mathrm{cm}^{3}\end{array}$ \\
\hline & Water temperature: $19{ }^{\circ} \mathrm{C}$ & $\begin{array}{l}\text { Time in which rill } \\
\text { occurs: } 6^{\prime} 15^{\prime \prime}\end{array}$ \\
\hline \multirow[t]{4}{*}{5} & Rainfall intensity: $2.06 \mathrm{~mm} / \mathrm{min}$ & $\begin{array}{l}\text { Inclination angle of slope: } \\
30^{\circ}\end{array}$ \\
\hline & Initial water content: $22.06 \%$ & $\begin{array}{l}\text { Water content after test: } \\
23.20 \%\end{array}$ \\
\hline & $\begin{array}{l}\text { Initial soil bulk density: } \\
1.69 \mathrm{~g} / \mathrm{cm}^{3}\end{array}$ & $\begin{array}{l}\text { Soil bulk density after } \\
\text { test: } 1.71 \mathrm{~g} / \mathrm{cm}^{3}\end{array}$ \\
\hline & Water temperature: $8^{\circ} \mathrm{C}$ & $\begin{array}{l}\text { Time in which rill } \\
\text { occurs: } 3^{\prime} 20^{\prime \prime}\end{array}$ \\
\hline
\end{tabular}

The results of all 1D experiments, as shown in Fig. 1, exhibited that when rills occurred on the slope, the quantity of soil eroded rapidly increased. Because of rills forming on the slope surface, overland flow formed concentrated flowlines which not only resulted in greater flow velocity on concentration routes than on other areas but also increased the erosion potential of flow. Rill flow and erosion is different from interrill flow (overland flow) and erosion. Thus, to accurately describe the concentrated flowlines of overland flow is essential for simulation of the runoff generation and erosion process.
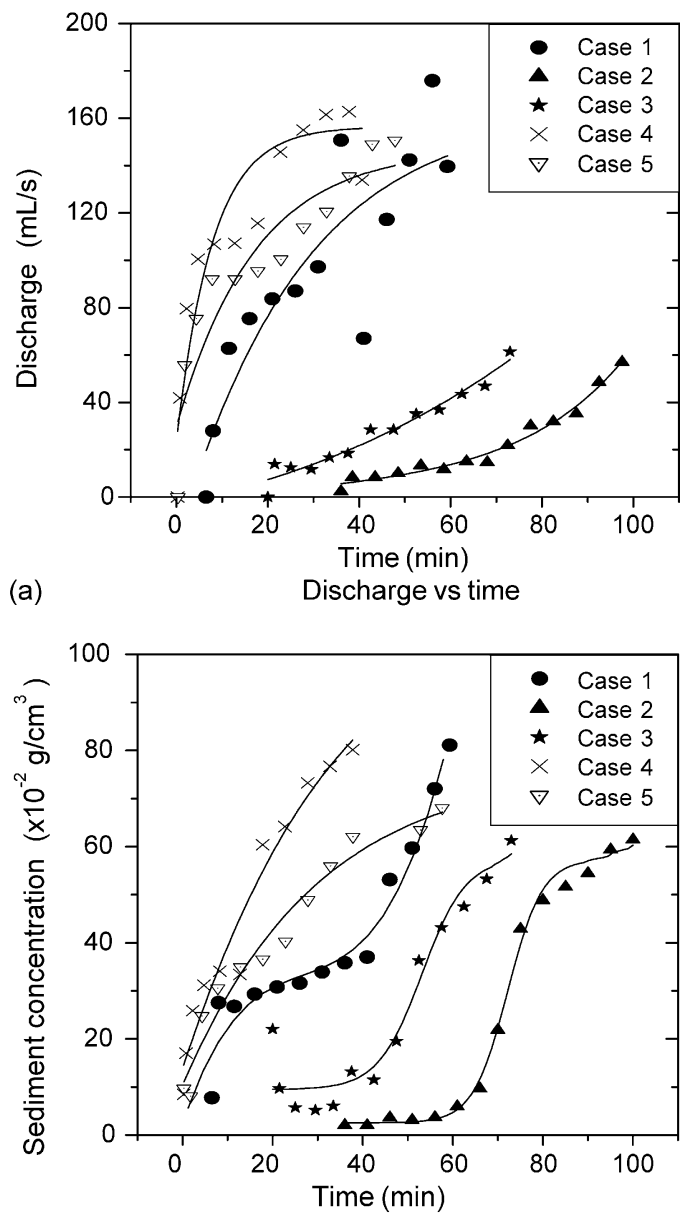

(b) Sediment concentration vs time

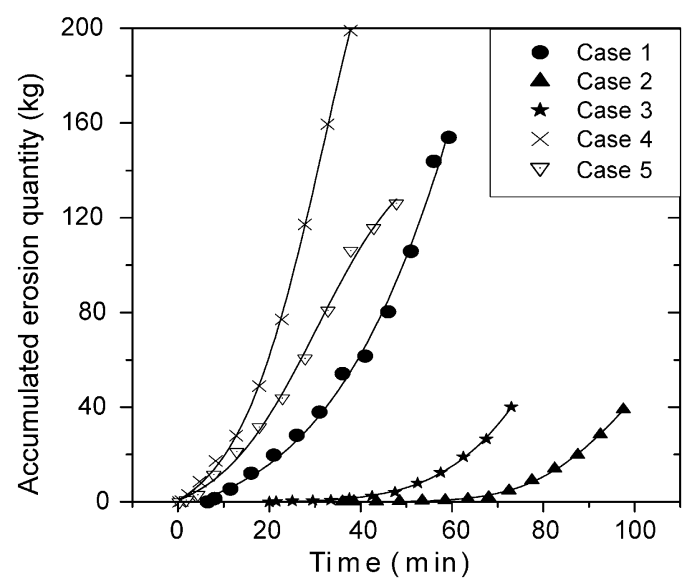

(c) Accumulated erosion quantity vs time

Fig. 1. Experimental results of discharge, sediment concentration and accumulated erosion quantity as functions of time. 
Furthermore, hillslopes have, in general, lots of grooves or large landform waves on their surfaces, i.e. their surfaces are very irregular. Thus, to correctly simulate the concentrated flow hydraulics is a necessary first step for simulating the erosion potential. The 1D kinematic wave model was not able to accurately simulate the concentrated overland flow because it is an averaged model in the transverse direction for the whole slope. This constituted the basis for developing the 2D kinematic wave model.

\subsection{Extension of kinematic wave model from $1 D$ to $2 D$}

The overland flow concentration on an irregular hillslope is $2 \mathrm{D}$ and its simulation, therefore, requires a 2D flow model. The model developed in this study integrates two important process scales: the small scale and the large scale. Two kinds of 2D topographies were considered in the model formulation and its application, i.e. the simple slope surface with small grooves and the complex hillslope with large landform undulations. For simple slopes with small grooves, the small scale was useful for distinguishing flowline concentrations and contributing interrill areas, and was, thus, the appropriate scale for analysis of the mechanics of runoff erosion, especially rill erosion. For complex hillslopes with large landform irregularities (rise and fall), the large scale was useful for predicting the overland flow confluent process and revealing large-scale dynamics of runoff and erosion potential, and was, thus, the appropriate scale for management strategies.

It is difficult to employ the full St Venant equations in two dimensions because of the complex boundaries of the slope and low water depths. The kinematic wave theory (Lighthill and Witham, 1955) is widely accepted for modeling overland flow, partly because it is simple and reasonably accurate. Therefore, it was considered appropriate to extend the theory from its $1 \mathrm{D}$ form to $2 \mathrm{D}$ form for describing the $2 \mathrm{D}$ overland flow on hillslopes. In general, one can write out the continuity equation:

$\frac{\partial h}{\partial t}+\frac{\partial q_{x}}{\partial x}+\frac{\partial q_{y}}{\partial y}=p \cos \theta-i$

where $x$ and $y$ are the spatial coordinates of a point on the hillslope and denote directions which are perpendicular to the slope located at this point; $t$ is the time (s); $h$ is the water depth (m); $q_{x}$ and $q_{y}$ are the unit discharge components in the $x$ and $y$ directions, respectively $\left(\mathrm{m}^{2} /\right.$ $\mathrm{s}) ; \theta$ is the inclination angle of slope (in degree); $p$ indicates the rainfall intensity $(\mathrm{m} / \mathrm{s})$; and $i$ represents the infiltration rate $(\mathrm{m} / \mathrm{s})$.

The main assumption of the kinematic wave model is that the gravity component along the slope is equal to the resistance force, thus a unique relation between discharge and water depth is established by using existing open channel flow friction equations. For example, Manning's friction equation is commonly applied to describe the discharge as a function of water depth, i.e. $q=U h=(1 / n) h^{5 / 3} S_{0}^{1 / 2}$ ( $U$ is the runoff velocity in flow direction, $S_{0}$ is the slope gradient along flow direction, $n$ is the Manning roughness coefficient). Since Manning's equation involves the energy gradient in the direction the flow is to be described, the kinematic wave theory can be extended to its $2 \mathrm{D}$ form is a similar manner.

To apply kinematic wave theory to $2 \mathrm{D}$ cases, Tayfur and Kavvas (1994; Tayfur, 2001) applied following expressions:

$$
\left\{\begin{array}{l}
q_{x}=U_{x} h=\frac{1}{n} h^{5 / 3} \frac{S_{0 x}^{1 / 2}}{\left(1+\left(\frac{S_{0 y}}{S_{0 x}}\right)^{2}\right)^{1 / 4}} \\
q_{y}=U_{y} h=\frac{1}{n} h^{5 / 3} \frac{S_{0 y}^{1 / 2}}{\left(1+\left(\frac{S_{0 x}}{S_{0 y}}\right)^{2}\right)^{1 / 4}}
\end{array}\right.
$$

where $U_{x}$ and $U_{y}$ are the velocity components in the $x$ and $y$ directions, respectively, $(\mathrm{m} / \mathrm{s})$; and $S_{0 x}$ and $S_{0 y}$ are the slope gradient components along the $x$ and $y$ directions, respectively. A closer examination shows that the above expressions can be further expressed in following form:

$$
\left\{\begin{aligned}
q_{x} & =\frac{1}{n} h^{5 / 3} S_{0 x}^{1 / 2}\left(\frac{S_{0 x}}{S_{0}}\right)^{1 / 2}=\frac{1}{n} h^{5 / 3} S_{0}^{1 / 2} \frac{S_{0 x}}{S_{0}} \\
& =U h \frac{S_{0 x}}{S_{0}}=h U \cos \gamma=q \cos \gamma \\
q_{y} & =\frac{1}{n} h^{5 / 3} S_{0 y}^{1 / 2}\left(\frac{S_{0 y}}{S_{0}}\right)^{1 / 2}=\frac{1}{n} h^{5 / 3} S_{0}^{1 / 2} \frac{S_{0 y}}{S_{0}} \\
& =U h \frac{S_{0 y}}{S_{0}}=h U \sin \gamma=q \sin \gamma
\end{aligned}\right.
$$


where $\gamma$ is the angle between the real flow direction and the $x$ direction. Obviously, these expressions originate from the 1D formulation of the kinematic wave theory. The above equations show that the runoff discharge (or flow velocity) calculated by the 1D kinematic wave theory can be divided into the $x$ and $y$ directions according to the flow direction. Thus, one feasible way is to introduce $2 \mathrm{D}$ grids on the slope surface, where the flow in a cell is simulated by the 1D kinematic wave model at first, and then is further divided into the $x$ and $y$ directions. A different flowline route is specified in every grid, and then the inflow and the outflow discharges of adjacent grids are calculated.

\subsection{Two-dimensional kinematic wave model}

It is difficult to get an analytical solution of $2 \mathrm{D}$ kinematic wave equations over irregular surfaces. Thus, a numerical 2D kinematic wave model, which can adequately reflect the runoff concentration process, was developed. The basic premise employed in the model is as follows: the 2D hillslope was partitioned into cells (or grid elements) and the kinematic wave model was applied to simulate overland flow in every cell. Then, cells were connected to each other by distinguishing the flow direction in every cell and the flow discharge was divided into $x$ and $y$ directions according to the geometry of the topography of every cell. Finally, runoff was computed for the whole hillslope.

\subsubsection{Kinematic wave equation in a computational element}

In a cell (or a computational element), the kinematic wave model was applied to describe the overland flow, which can be expressed as:

$$
\left\{\begin{array}{l}
\frac{\partial h}{\partial t}+\frac{\partial q_{x}}{\partial x}+\frac{\partial q_{y}}{\partial y}=p \cos \theta-i \\
q=U h=\frac{1}{n} h^{5 / 3} S_{0}^{1 / 2} \\
q_{x}=q \cos \gamma \\
q_{y}=q \sin \gamma
\end{array}\right.
$$

where $q$ is the unit width discharge of runoff in the flow direction; $U$ is the runoff velocity in flow direction, $h$ is the water depth, $S_{0}$ is the slope gradient along the flow direction. $q_{x}$ and $q_{y}$ are the unit width discharge components in the $x$ and $y$ directions, respectively; and $\gamma$ is the angle between the flow direction and the $x$ coordinate.

\subsubsection{Grid partition and runoff disintegration in a cell}

As shown in Fig. 2(a), the hillslope surface is partitioned into rectangular grids or cells. A rectangular grid is the projection of the grid onto the horizontal plane. In fact, the four points of an element in the practical space are not in the same plane as shown in Fig. 2(b). After the cell units are ascertained, the next step is to describe the slope gradient and the flow direction in the cell (see Fig. 2(c)). Based on the experimental results, the concentration flowlines of overland flow mainly depend on the landform of the hillslope. Thus, it may be assumed that the flow direction in a cell is fully dependent on the geometry of its topography. As a result, the flow direction in a cell can be deduced from its geometric expression.

Assuming the element plane as a bilinear element, one can express:

$z=(a x+b)(c y+d)$

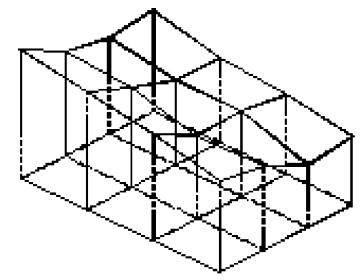

(a) Sketch of 2-D grids

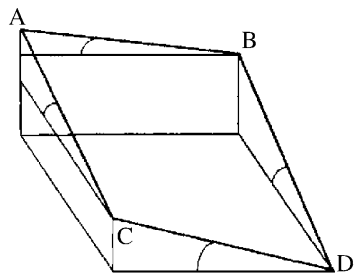

(b) Sketch of cell dimension

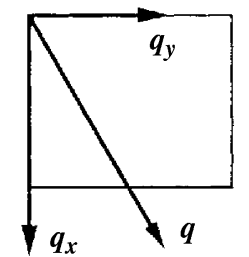

(c) Cell flowline disintegration

Fig. 2. Cells partition and cell flowline analysis. 
where $z$ is the height of the element; and $x$ and $y$ are the abscissa and ordinate, respectively. From Eq. (5), the relation between $z$ and $y$ is always linear for a fixed $x$ and the relation between $z$ and $x$ is linear for a fixed $y$.

Transforming the projection area of the element to the fixed area $[-1,1] \times[-1,1]$, the transformed element can be expressed as:

$z=\sum_{i=1}^{4} N_{i} z_{i}$

where $i$ is serial number of the four corners of the element, $z_{i}$ is the height of the $i$-th corner, and $N_{i}$ is the interpolating function expressed as

$N_{i}=\frac{1}{4}\left(1+\xi_{i} \xi\right)\left(1+\eta_{i} \eta\right)$

The forms of the element grids before and after transformation are as shown in Fig. 3. The $\mathrm{d} x$ and $\mathrm{d} y$ values are the projections on the horizontal plane of the grid step lengths in the $x$ and $y$ directions, respectively.

The coordinate transformation relation is

$\xi=2 \frac{x-x_{c}}{x_{\mathrm{B}}-x_{\mathrm{A}}}, \quad \eta=2 \frac{y-y_{c}}{y_{\mathrm{B}}-y_{\mathrm{A}}}$

where

$x_{c}=\frac{1}{2}\left(x_{\mathrm{A}}+x_{\mathrm{B}}\right), \quad y_{c}=\frac{1}{2}\left(y_{\mathrm{A}}+y_{\mathrm{B}}\right)$.

If $z$ is replaced by $z=f(x, y)=F(\xi, \eta)$, we have

$\operatorname{Grad} f(x, y)=\frac{\partial f}{\partial x} i+\frac{\partial f}{\partial y} j=\frac{\partial F}{\partial \xi} \frac{2}{\mathrm{~d} x} i+\frac{\partial F}{\partial \eta} \frac{2}{\mathrm{~d} y} j$

$\operatorname{Grad} F(\xi, \eta)=\frac{\partial F}{\partial \xi} i+\frac{\partial F}{\partial \eta} j$
Assuming the slope gradient of the center point of the element as the slope gradient of the whole element, the representative slope gradient $\theta$ can be obtained as:

$\tan \theta=|\operatorname{Grad} f(x, y)|$

$$
=\sqrt{\left(\frac{\partial F}{\partial \xi}\right)^{2} \frac{4}{\mathrm{~d} x^{2}}+\left(\frac{\partial F}{\partial \eta}\right)^{2} \frac{4}{\mathrm{~d} y^{2}}}
$$

and the flow vector direction angle $\gamma$ as

$\tan \gamma=\frac{\partial f}{\partial y} / \frac{\partial f}{\partial x}=\frac{\mathrm{d} x}{\mathrm{~d} y} \frac{\partial F}{\partial \eta} / \frac{\partial F}{\partial \xi}$

The quantities, $\partial F / \partial \xi$ and $\partial F / \partial \eta$, can be obtained from the expression of the bilinear element:

$$
\begin{aligned}
\frac{\partial F}{\partial \xi} & =\sum_{i=1}^{4} \frac{1}{4} \xi_{i}\left(1+\eta_{i} \eta\right) z_{i} \\
& =\frac{1}{4}\left(z_{1}+z_{2}-z_{3}-z_{4}\right) \\
\frac{\partial F}{\partial \eta} & =\sum_{i=1}^{4} \frac{1}{4} \eta_{i}\left(1+\xi_{i} \xi\right) z_{i} \\
& =\frac{1}{4}\left(z_{1}-z_{2}-z_{3}+z_{4}\right)
\end{aligned}
$$

The average length of each element in space can be expressed by $\Delta x$ and $\Delta y$ :

$\Delta x=\mathrm{d} x / \arctan \left(\frac{\partial f}{\partial x}\right), \Delta y=\mathrm{d} y / \arctan \left(\frac{\partial f}{\partial y}\right)$

Assuming the flow direction is controlled completely by the landform, the water in every element is considered to flow out along the flow direction, and then flow into two adjacent grids. If the unit discharge is $q$, the unit discharges in the $x$ and $y$ directions can be
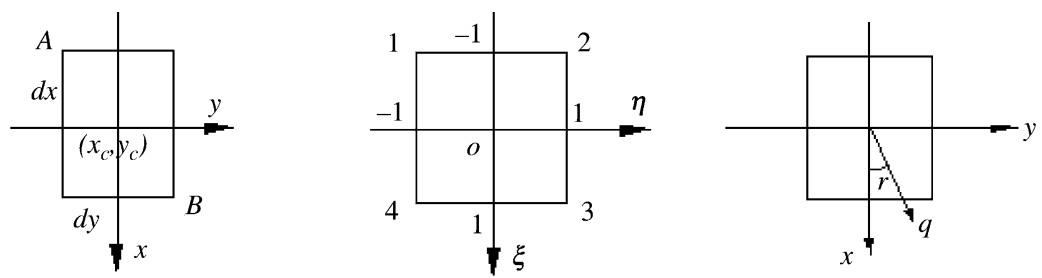

(a) Cell projection in horizontal plane (b) Coordinate transformation

(c) Flowline direction in a cell

Fig. 3. Cell projection in horizontal plane, coordinate transformation and serial number. 
calculated, respectively, as:

$q_{x}=q \cos \gamma, \quad q_{y}=q \sin \gamma$

In this model, the flow is not assumed to concentrate at the center point of the cell. Instead, the water may flow out from any point of the cell along the flow direction angle and flow into two neighbour cells. That is, the water of every cell may flow out from two sides of the cell and flow into two neighbouring cells. At the same time, every cell may receive inflow from 0 to 4 directions: from up slope, down slope, left slope and right slope as well.

\subsubsection{Computational format}

The flow continuum equation can be written as:

$\frac{\partial h}{\partial t}+\frac{\partial F_{x}}{\partial x}+\frac{\partial F_{y}}{\partial y}=S r$

where $F_{x}$ and $F_{y}$ express the unit discharge components in the $x$ and $y$ directions, respectively; and $\mathrm{Sr}$ is the source item. Taking the calculation point at the center of a grid, the finite volume difference expression of Eq. (16) can be written as:

$$
\begin{aligned}
h_{i, j}^{n+1}= & h_{i, j}^{n}-\frac{\Delta t}{\Delta \bar{x} \Delta \bar{y}}\left(F_{x i+1 / 2, j} \Delta Y_{i+1 / 2, j}\right. \\
& -F_{x i-1 / 2, j} \Delta Y_{i-1 / 2, j}+F_{y i, j+1 / 2} \Delta X_{i, j+1 / 2} \\
& \left.-F_{y i, j-1 / 2} \Delta X_{i, j-1 / 2}\right)+S r_{i, j}^{n+1} \Delta t
\end{aligned}
$$

where $\Delta t$ is the time step of calculation; $\Delta \bar{x}$ and $\Delta \bar{y}$ are the lengths of the calculation grid unit in the $x$ and $y$ directions, respectively; and $\Delta X$ and $\Delta Y$ with subscript are the real lengths of the cell in the $x$ and $y$ directions, respectively.

Because every element does not have only an inflow cell and an outflow cell, applying the first-order backward difference operator, the inflow unit discharge during $\Delta t$ in the $x$ direction can be written as:

$$
\begin{aligned}
F_{x_{i-1 / 2, j}} \Delta Y_{i-1 / 2, j} \Delta t= & {\left[\max \left(q_{x_{i-1, j}}, 0\right) \Delta y_{i-1 / 2, j}\right.} \\
& \left.-\min \left(q_{x_{i+1, j}}, 0\right) \Delta y_{i+1 / 2, j}\right] \Delta t
\end{aligned}
$$

and the inflow unit discharge during $\Delta t$ in the $y$ directions is

$$
\begin{aligned}
F_{y_{i, j-1 / 2}} \Delta X_{i, j-1 / 2} \Delta t= & {\left[\max \left(q_{y_{i, j-1}}, 0\right) \Delta x_{i, j-1 / 2}\right.} \\
& \left.-\min \left(q_{y_{i, j+1}}, 0\right) \Delta x_{i, j+1 / 2}\right] \Delta t
\end{aligned}
$$

During $\Delta t$, the outflow discharge components in the $x$ and $y$ directions can be written, respectively, as:

$F_{x_{i+1 / 2, j}} \Delta Y_{i+1 / 2, j} \Delta t=q_{x_{i, j}}\left\{\begin{array}{ll}\Delta y_{i+1 / 2, j}, & q_{x_{i, j}} \geq 0 \\ \Delta y_{i-1 / 2, j}, & q_{x_{i, j}}<0\end{array}\right\} \Delta t$

$$
\begin{aligned}
& F_{y i, j+1 / 2} \Delta X_{i, j+1 / 2} \Delta t \\
& =q_{y i, j}\left\{\begin{array}{ll}
\Delta x_{i, j+1 / 2}, & q_{y_{i, j}} \geq 0 \\
\Delta x_{i, j-1 / 2}, & q_{y_{i, j}}<0
\end{array}\right\} \Delta t
\end{aligned}
$$

where $\Delta X_{i, j-1 / 2}$ and $\Delta Y_{i-1 / 2, j}$ represent the side lengths of an upstream cell in the $x$ and $y$ directions, respectively, $\Delta X_{i, j+1 / 2}$ and $\Delta Y_{i+1 / 2, j}$ represent the side lengths of a downstream cell in the $x$ and $y$ directions, respectively; and $\Delta x_{i, j-1 / 2}, \Delta y_{i-1 / 2, j}, \Delta x_{i, j+1 / 2}$ and $\Delta y_{i+1 / 2, j}$ are the actual lengths of four sides of a cell, respectively.

\subsubsection{Infiltration model}

The soil infiltration was simulated with the revised Green-Ampt model (Mein and Larson, 1973) which can be written as:

$i=\frac{\mathrm{d} I}{\mathrm{~d} t}=K\left[1+\left(\theta_{S}-\theta_{i}\right) S / I\right]$

$I=K t+S\left(\theta_{s}-\theta_{i}\right) \ln \left(1+\frac{I}{S\left(\theta_{s}-\theta_{i}\right)}\right)$

where $I$ is cumulative infiltration quantity $(\mathrm{m}), i$ is the infiltration rate $(\mathrm{m} / \mathrm{s}), K$ is the saturated hydraulic conductivity of the soil (or infiltration coefficient) $(\mathrm{m} / \mathrm{s})$, $\theta_{s}$ is the saturated volumetric water content, i.e. the effective porosity $(\%), \theta_{i}$ is the initial volumetric water content $(\%)$, and $S$ is the soil suction (m).

The Green-Ampt equation is applied to ponding water infiltration on dry soils. Mein and Larson (1973) generalized it to infiltration during rainfall. Suppose $p$ is the steady rainfall intensity. In the initial stage of rainfall, the entire rainfall infiltrates into the soil, and the infiltration rate decreases with cumulative infiltration. At the moment when $i$ equals $p$, the ponding occurs according to the Hortonian mechanism. The cumulative infiltration at the time, $I_{p}$, can be derived 
by the Green-Ampt equation as

$I_{p}=\frac{\left(\theta_{s}-\theta_{i}\right) S}{p / K-1}$

from which the ponding time is obtained as

$t_{p}=I_{p} / p$

Thus, the infiltration rate can be expressed as

$$
\begin{array}{lll}
i=p & t \leq t_{p} \\
\left.i=K\left[1+\left(\theta_{s}-\theta_{i}\right) S / I\right]\right] & t>t_{p}
\end{array}
$$

where $I$ is the cumulative infiltration depth after ponding (including $I_{p}$ ). Since ponding does not occur at $t=0$, the infiltration equation is revised as

$$
\begin{aligned}
& K\left[t-\left(t_{p}-t_{s}\right)\right] \\
& \quad=I-S\left(\theta_{s}-\theta_{i}\right) \ln \left[1+\frac{I}{S\left(\theta_{s}-\theta_{i}\right)}\right]
\end{aligned}
$$

in which $t_{s}$ represents the time from $t=0$ to the time when $I=I_{p}$ (or $i=p$ ). It is assumed that ponding occurs at $t=0$, i.e. taking the first stage of rainfall infiltration (before ponding) as ponding infiltration. Therefore, $t_{s}<t_{p}, t_{s}$ can be viewed as a pseudo time. Thus,

$K t_{s}=I_{p}-S\left(\theta_{s}-\theta_{i}\right) \ln \left[1+\frac{I_{p}}{S\left(\theta_{s}-\theta_{i}\right)}\right]$

The main idea of revising the original Green-Ampt equation is to assume the entire process as ponding infiltration from the beginning. Therefore, the whole curve, since ponding starts, should be translated to the left by $t_{p}-t_{s}$. By translating this curve back to the right by $t_{p}-t_{s}$, one gets the real infiltration.

\section{Experimentation}

The process of runoff generation and flow concentration on a hillslope with an up-and-down landform was investigated experimentally using the same soil in the same laboratory. The soil was packed into the wooden box with holes at the bottom, and was controlled to reach a bulk density of $1.3 \mathrm{~g} / \mathrm{cm}^{3}$. The slope gradient of the soil box was secured at $10^{\circ}$. The initial surface landform was an irregular surface,

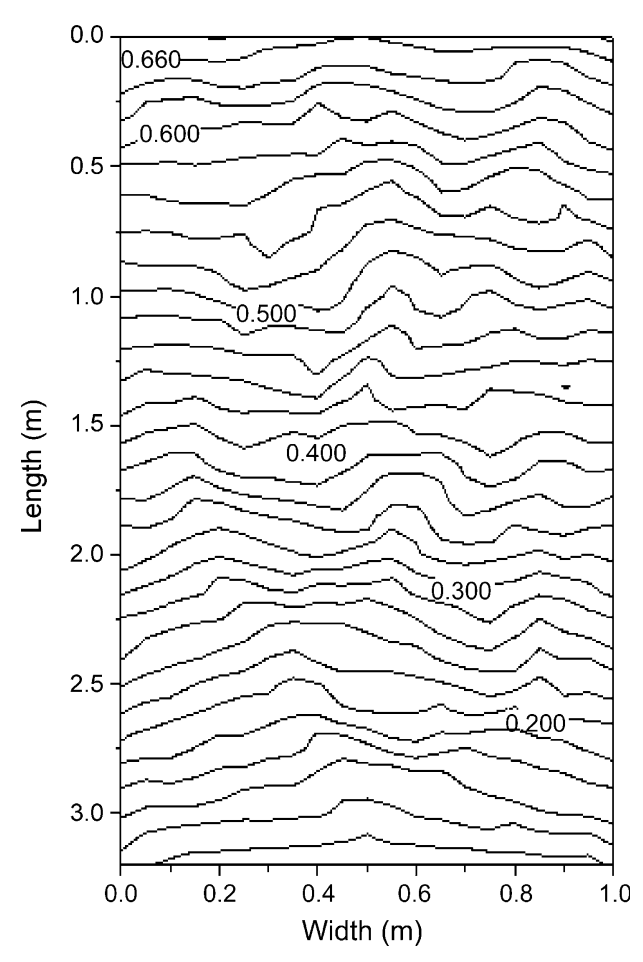

Fig. 4. Geomorphic contours of test-slope (Unit: m).

which was artificially made as shown in Fig. 4. It exhibited three main grooves on the slope surface.

Before the experiment, the bulk density, moisture content and porosity of the soil were measured by using a ring sampler (the bulk density of soil was $1.33 \mathrm{~g} / \mathrm{cm}^{3}$, the moisture content of soil was $22.62 \%$, and the porosity of the soil was $50.27 \%$ ). The rainfall intensity adopted in this experiment was $1.6 \mathrm{~mm} / \mathrm{min}$, and the rainfall duration was $1 \mathrm{~h}$. The runoff volume at the test-plot outlet was measured, and the flow mean velocities of several specific points were also measured using stained method at different times from the beginning of runoff formation. The stained method is a simple method to measure the mean velocity of overland flow. A slug of dye was injected into overland flow and the time required for the concentration peak to travel a known distance to a downstream point was identified. The velocity associated with the peak concentration was assumed to equal the mean velocity of overland flow. Thus the flow mean velocity was obtained by dividing travel distance by time of travel. 


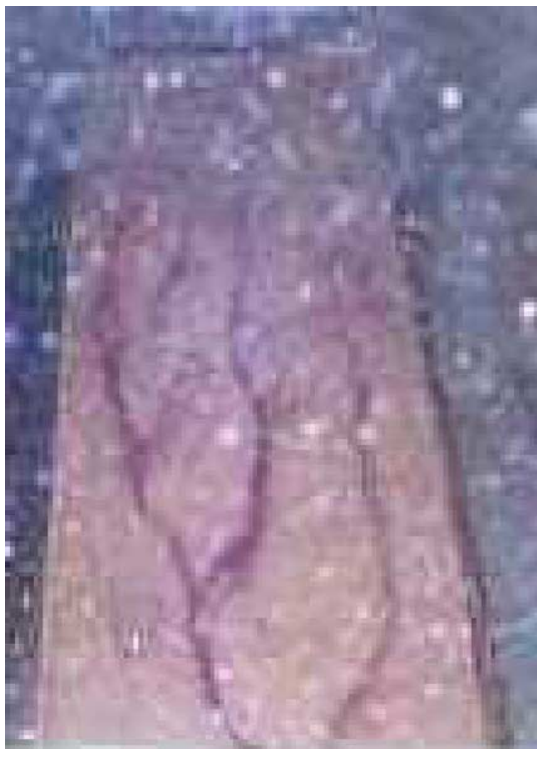

Fig. 5. Flow visualization results of concentrated flow on the slope.

Fig. 5 shows the flow concentration routes of overland flow observed in the experiment. Experimental results show that the overland flow formed three obvious concentration flow routes on the slope, and exhibited a good agreement with what is reflected in Fig. 4. This phenomenon shows that the geometry of the topography of hillslope surface controls the concentration flowlines of overland flow. Because the overland flow depth was very shallow, small grooves on the slope led to flow accumulation into low places, and formed flow concentration routes. The concentration flowlines depended on the geometry of the topography of the slope surface.

\section{Validation and comparison of model}

\subsection{Model validation}

Using the proposed model, the process of runoff generation and flow route concentration on the test-plot were simulated The model parameters used in simulation are shown in Table 2 . The size of the grids was set as $5 \times 5 \mathrm{~cm}^{2}$ according to the measured values of the landform. The number of grids was $64 \times 20$. The computation time interval was set as $0.1 \mathrm{~s}$. The simulation results are shown in Figs. 6-8.

Fig. 6 compares observed and predicted runoff volumes and total discharges at the outlet of the testplot. Because the runoff generated was indirectly obtained from the experimental observations of runoff volume, its precision was a little lower. But on the whole, the agreement between observed and predicted results was good, except during the very short initial period. This comparison also shows that the proposed model is capable of adequately simulating the process of runoff generation on the hillslope.

Fig. 7 shows distributions of simulated flow depths and unit discharges on the entire test-plot at the runoff steady state. In the figure, the position with big values of the water depth is just the position where the water starts to concentrate on a route. Compared to the experimental results of Fig. 5, the agreement between simulation results and experimental observations is good. In experiment, the flow velocities of some points located at different positions on the slope were measured by the stained method. At same time, the flow velocities of these points were calculated by this model. Fig. 8 compares observed and predicted flow velocities at different points and shows a good agreement between them for most points. Of course, at some points velocities observed in the experiment are obviously greater than the calculated values. This may be caused by the erosion of the slope in the experiment which was not considered in the model simulation.

\subsection{Comparison with Scoging's model}

For comparison, the overland flow concentration was simulated on the small test-plot by the proposed

Table 2

Characteristic parameters of soil used in calculation

\begin{tabular}{llll}
\hline $\begin{array}{l}\text { Porosity of soil } \\
\text { (respectively) }\end{array}$ & $\begin{array}{l}\text { Initial water content } \\
\text { (respectively) }\end{array}$ & $\begin{array}{l}\text { Permeability coefficient } \\
(\mathrm{mm} / \mathrm{min})\end{array}$ & $\begin{array}{l}\text { Soil suction } \\
(\mathrm{m})\end{array}$ \\
\hline 50.27 & 22.62 & 0.1 & 0.15 \\
\hline
\end{tabular}



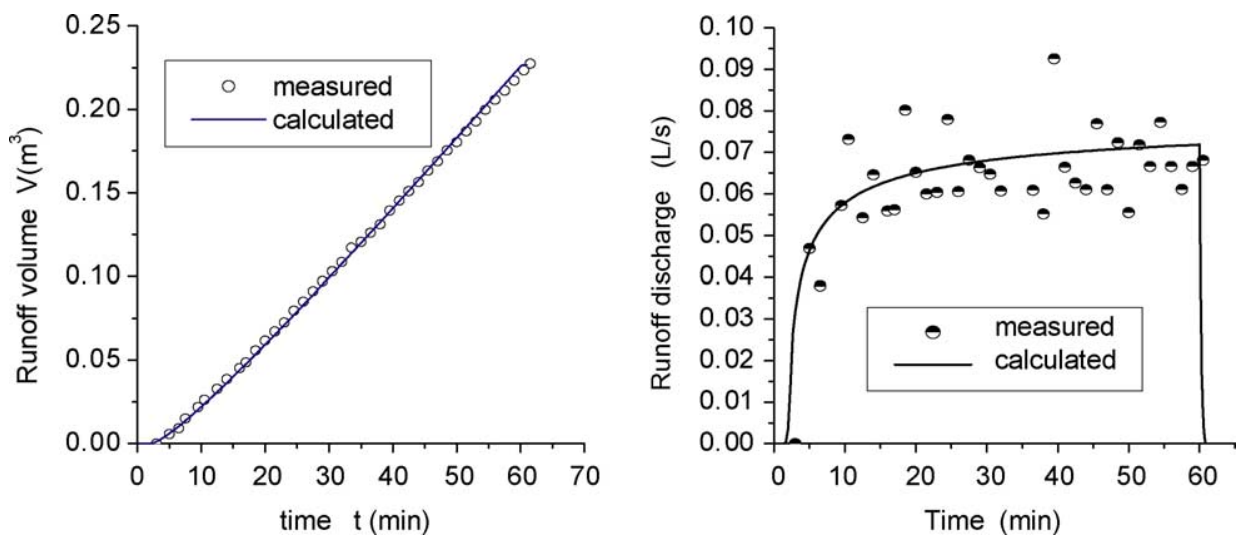

Fig. 6. Comparison of observed and predicted runoff volume and discharge at the outlet section.

model and Scoging's model. First, Scoging's model cannot simulate the experimental process under the conditions of the present test. This is because in Scoging's model the water only flows out from one boundary of a cell. In practical conditions, the water flows out from two lower side boundaries but one side boundary. Therefore, the use of the Scoging model might lead to erroneous simulation results in some situations.

As shown in Fig. 9, the flowline vector of every cell intersects its downstream side. According to Scoging's method, the flow distributed on both side

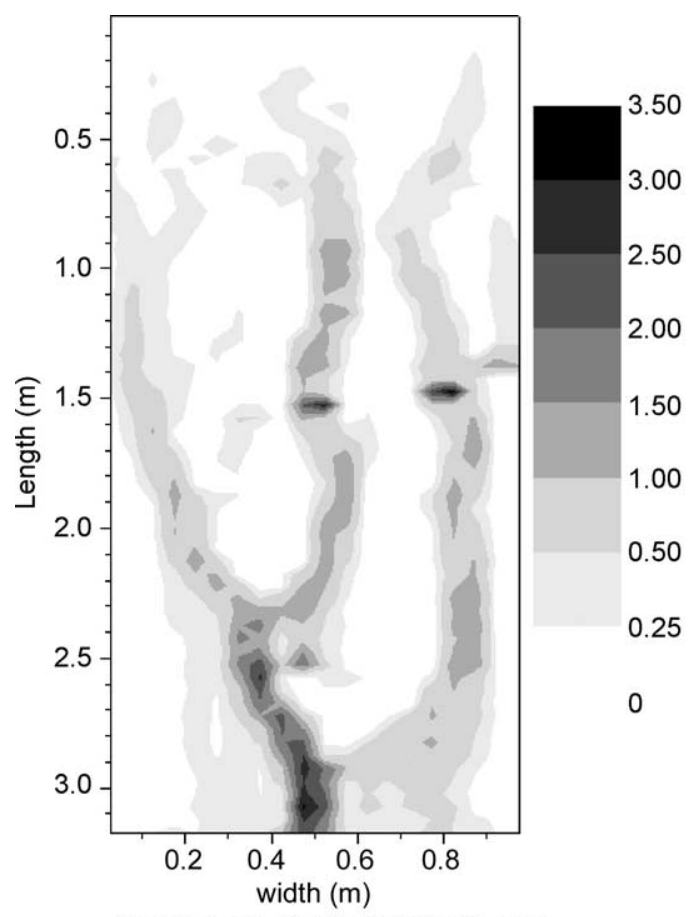

Water depth distribution (Unit: $\mathrm{mm}$ )

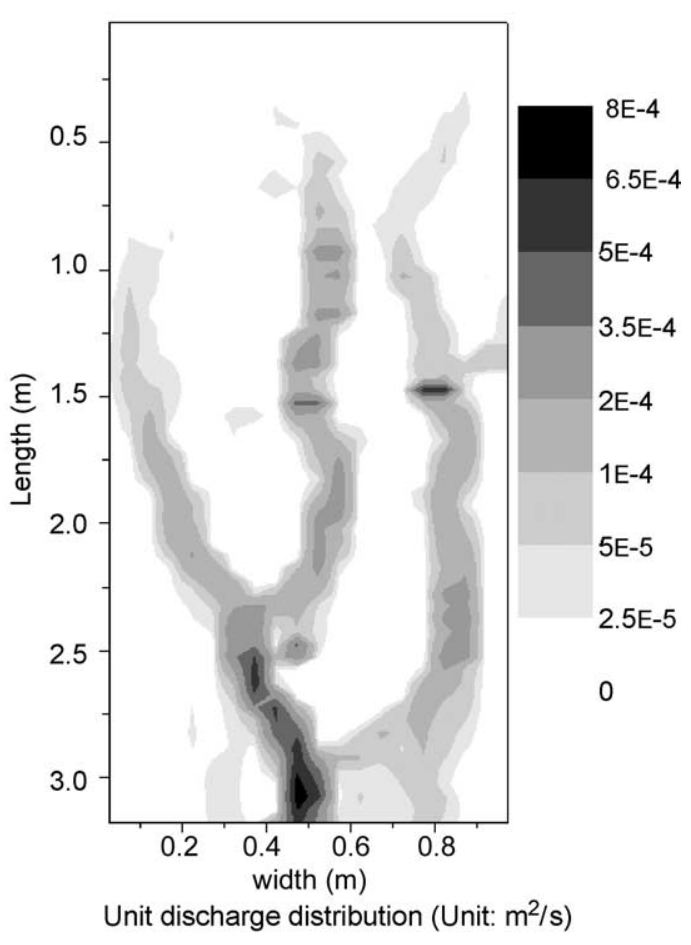

Fig. 7. Flowline route concentration caused by surface landform of slope (at steady state). 


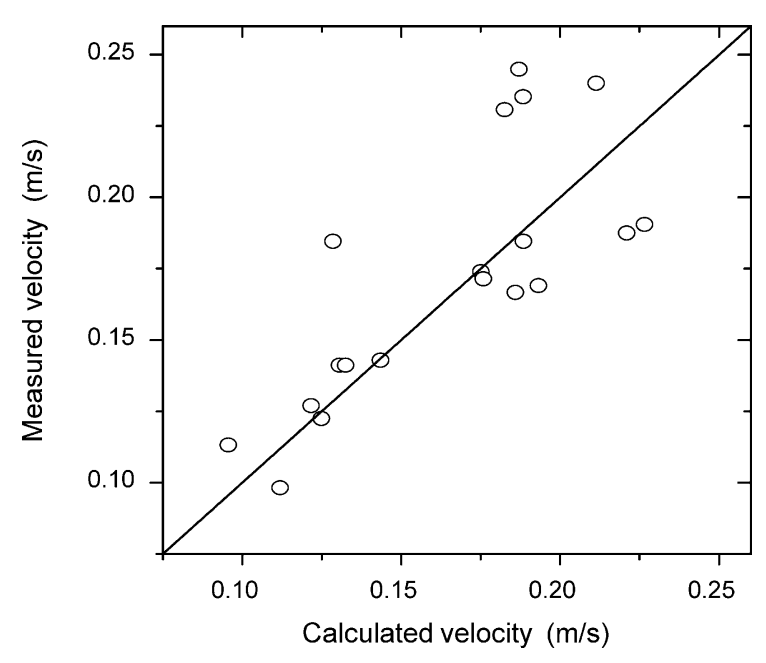

Fig. 8. Comparison of observed and predicted flow velocities.

cells will only flow down into its downstream cell, respectively, instead of concentrating into the middle cells, and form two unrealistic flowline routes. As a matter of fact, the flow on both side cells will converge into the middle cell, and form a concentrated flow route. Thus, under the situation shown in Fig. 9, the Scoging model would obtain unrealistic flowlines in simulation. In addition, when two neighbouring cells are located on the two sides of a groove, the flow vectors may point to each other if the slope gradient is not greater. Consequently, the water in these two cells will not have an outlet, thus leading to endless accumulation in the two cells. Such a situation is encountered in the small test-plot, and therefore

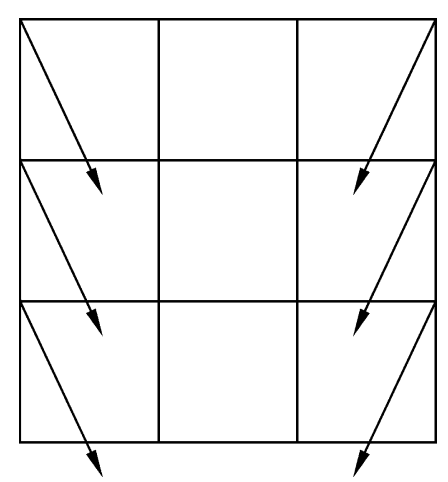

Fig. 9. Sketch of flow concentration along flowline vector.
Scoging's flowline analysis leads to erroneous calculations.

For comparing the two models, the plane area of the test-plot was magnified to two times the initial area but the height of every point was kept constant. Thus, this reduced the local slope gradient on the testplot. Fig. 10(a) and (b) are the distributions of unit flow discharge at steady state on the present small test-plot simulated by the proposed model and Scoging's model, respectively. The simulation results by the proposed model are in good agreement with experimental results, but the results of the Scoging model do not correctly reflect the real pattern of overland flow concentration on the small test-plot.

\section{Confluence characteristics of overland flow on the slope}

A major factor affecting the confluent process of overland flow is the ratio of the width and depth of grooves existing on the slope surface. For analyzing the confluence characteristics of overland flow, a slope was designed that abides by the following equation:

$z=(L-x) \sin \theta+0.5\left[1-\sin \left(\frac{y}{\mathrm{~B}} \pi\right)\right]$

where $x$ is the coordinate along the downward direction of slope $(\mathrm{m}) ; y$ is the horizontal coordinate along the width direction of slope; $L$ is the length of slope and $B$ is the width of the projection of slope in the horizontal plane; and $\theta$ is the slope gradient. Thus, the slope is a curved surface with a straight line in longitudinal direction and a sin curve line as shown in Fig. 11.

Using the kinematic wave model presented here, the confluence characteristics of overland flow on the slope were analyzed. Keeping the calculation conditions invariable (with the parameters of the numerical experiment adopted), the runoff generation on four slopes with $5,10,15$, and $20 \mathrm{~m}$ widths was investigated numerically. The distributions of several main hydraulic factors (unit discharge, flow depth, velocity, and shear stress) of overland flow on the longitudinal section in the slope middle line were compared, respectively, under the conditions of 


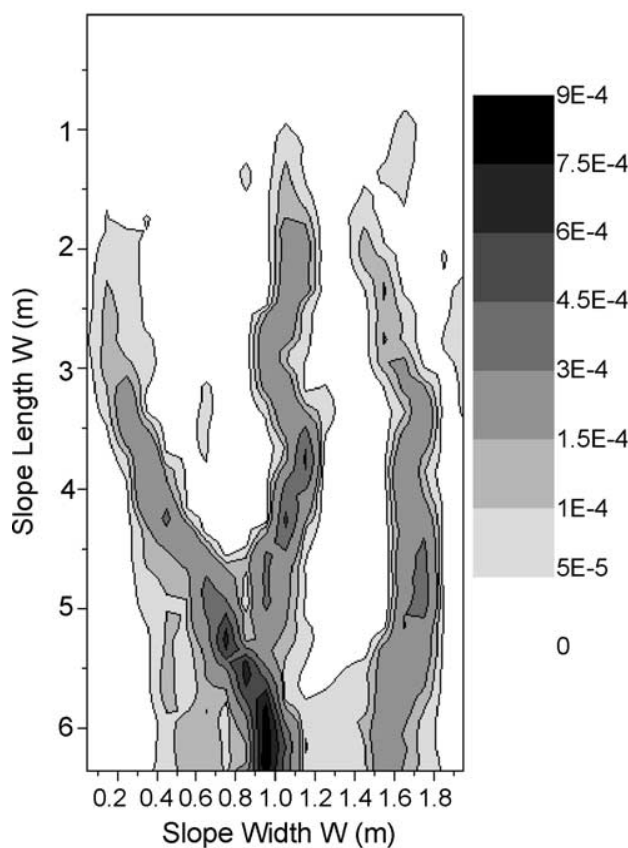

(a) Simulated by the proposed model

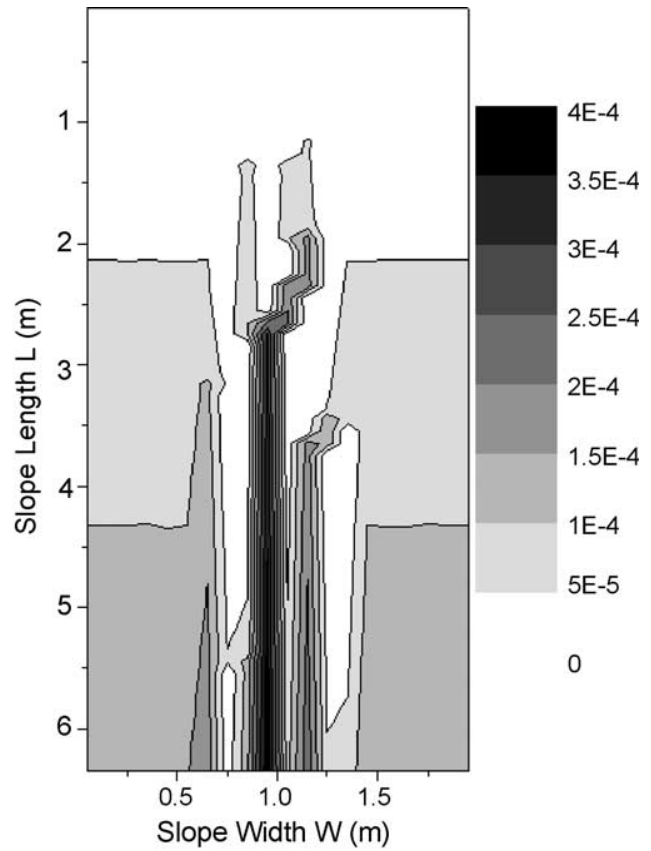

(b) Simulated by Scoging's model

Fig. 10. Distributions of predicted unit flow discharge of runoff at steady state (Unit: $\mathrm{m}^{2} / \mathrm{s}$ ).

different confluent widths. The results of numerical simulation are shown in Fig. 12.

The results indicate that increasing the confluence width does not augment the intensity of the concentrated flow but may have an inverse influence to some degree. In the upstream part of the slope, each hydraulic factor decreases along with the slope/confluence width increase. In the downstream part of the slope, each factor near the outlet is the largest for the slope with a $10 \mathrm{~m}$ width. Since the groove depth is unchanged, the slope gradients of the groove's two sides decrease with the slope width increase. The smaller the slope width is, the bigger the intersection angle between the main flow direction and the direction of water flow from two sides of the groove. Thus, the water flow can confluence into the main flow faster. Although a greater slope width can lead to the concentrated flow discharge which increases more quickly downstream along the slope, it can also lead to greater decrease in the transverse gradient of slopes of groove's two sides. Consequently, the velocities of the confluence flow from groove's two sides decrease. Under the action of both of them, the unit discharge, flow speed, water depth and shear stress, etc. are nearest to the outlet on the slope with a $10 \mathrm{~m}$ width. This phenomenon shows that the erosion ability of the concentrated flow is not directly proportional to the confluence width.

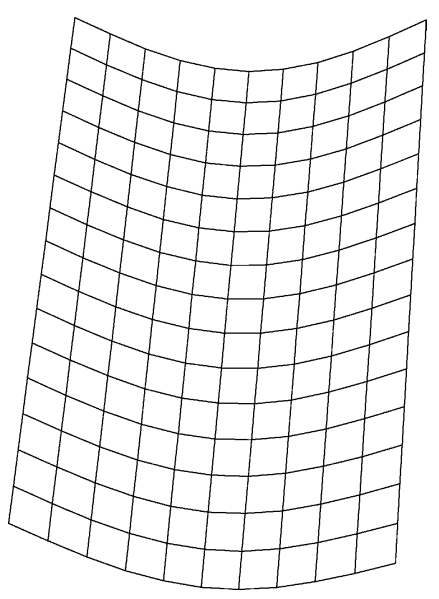

Fig. 11. The sketch of designed slope. 


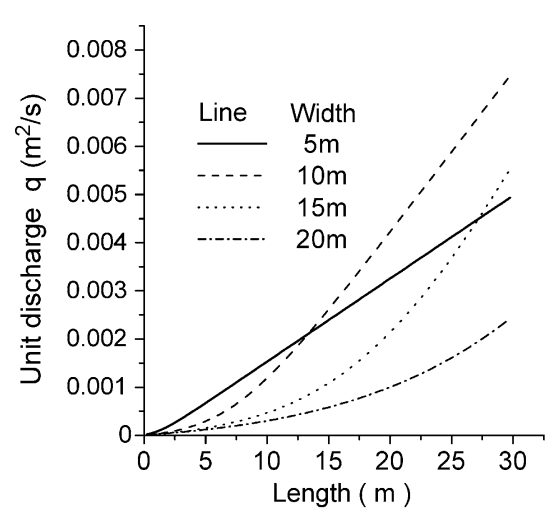

Balanced maximum unit discharge down the slope

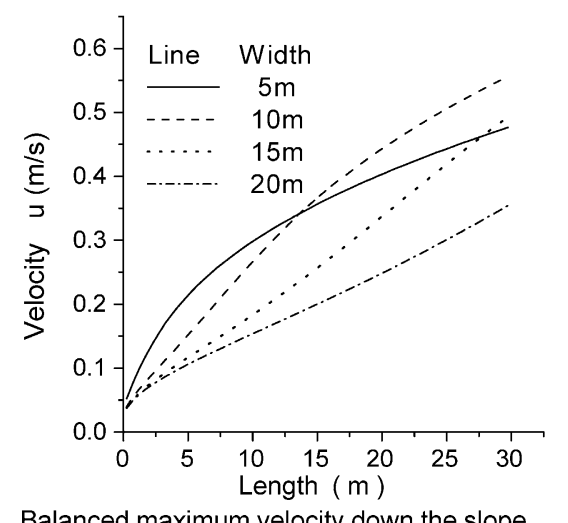

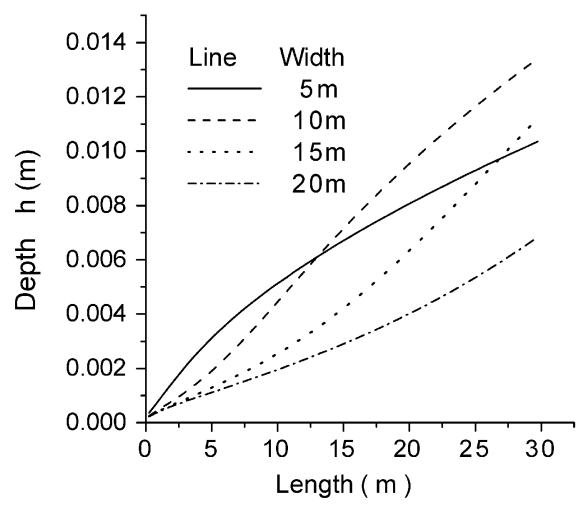

Balanced maximum water depth down the slope

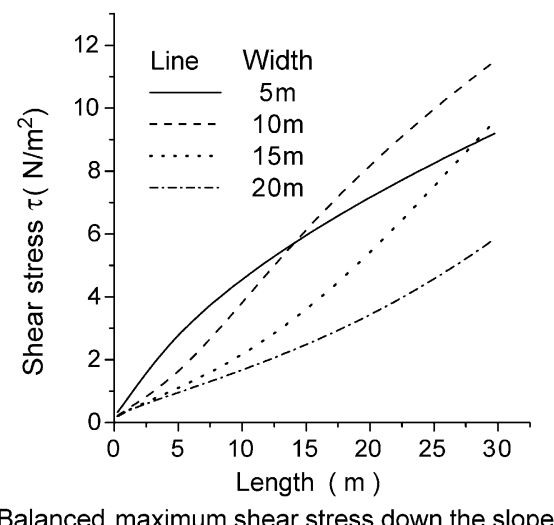

Fig. 12. Distributions of hydraulic factors of overland flow on the longitudinal section in the middle slope line under different confluent widths.

\section{Conclusions}

The following conclusions are drawn from this study:

(1) During runoff generation on hillslopes with irregular surfaces, overland flow often forms the flowline route by flow concentration. Experimental results show that the geometry of the topography of the slope surface is the main cause of the overland flow concentration.

(2) A 1D dynamic model generally used in overland flow is not able to simulate runoff generation and flowline concentration of overland flow on irregular slopes. Because of thin water depth and complex surface boundaries of a hillslope, it is difficult to apply the fully 2D dynamic model.
(3) One feasible way is to introduce $2 \mathrm{D}$ grids on the slope surface and simulate the flow in a cell by the kinematic wave model. A different flowline routine is specified in every grid and the inflow and the outflow discharge of the adjacent grids are calculated. Based on this idea, a quasi 2D kinematic wave model, which can adequately reflect the runoff concentration process, was developed. A laboratory experiment is used to verify the performance of the model. A good agreement between observed and predicted is found. In addition, comparison of simulation results of overland flow on the test-plot slope by two models shows that the proposed model is better than the Scoging model in simulating the overland flow concentration on irregular hillslopes. 
(4) Analysis of the confluence characteristics of overland flow by the model shows that the intensity of concentrated flow is not directly proportional to the confluent width of the hillslope, and is more dependent on the transvers slope gradient of two sides of groves to some extent.

\section{Acknowledgements}

This research was financially supported by the Key Projects of National Natural Science Foundation of China (No. 19832060 and No. 10332050) and by the Innovation Project Foundation of Chinese Academy of Sciences (No. KJCX2-SW-L1). Three figures 4, 6b, and $7 \mathrm{a}$ were reprinted from Advances in Applied Mechanics 39, Li, J.C., Liu, Q.Q., and Zhou J.F., Environmental Problems in China, pp. 217-306, Elsevier publication (2003), with permission from Elsevier.

\section{References}

Chen, L., Liu, Q.Q., Li, J.C., 2001a. Runoff generation characteristics in typical erosion regions on the Loess Plateau. International Journal of Sediment Research 16 (4), 473-485.

Chen, L., Liu, Q.Q., Li, J.C., 2001b. Study on the runoff generation process on the slope with numerical model. Journal of Sediment Research 4, 61-68.in Chinese

Cundy, T.W., Tento, S.W., 1985. Solution to the kinematic wave approach to overland flow routing with rainfall excess given by the Philip equation. Water Resources Research 21, 1132-1140.

Freeze, R.A., 1978. Mathematical models of hillslope hydrology. In: Kirkby, M.J., (Ed.), Hillslope hydrology, Wiley Interscience, New York, pp. 177-225.

Govindaraju, R.S., Kavvas, M.L., Tayfur, G., 1992. A simplified model for two-dimensional overland flows. Advances in Water Resources 15, 133-141.

Li, J.C., Liu, Q.Q., Zhou, J.F., 2003. Environmental Problems in China. Advances in Applied Mechanics 39, 217-306.

Lighthill, M.J., Witham, G.B., 1955. On kinematic waves 1: Flood movement in long rivers. Proceedings of the Royal Society A229, 281-316.

Mein, R.G., Larson, C.L., 1973. Modeling infiltration during a steady rain. Water Resources Research 9 (2), 384-394.

Scoging, H., 1992. Modeling Overland-Flow Hydrology for Dynamic Hydraulics In: Parsons, A.J., Abrahams, A.D. (eds), Overland Flow, UCL Press, pp 89-103.

Singh, V.P., 1996. Kinematic Wave Modeling in Water Resources: Surface Water Hydrology. Wiley, New York.

Tang, L.Q., Chen, G.X., 1997. The dynamic model of runoff generation and sediment yield in small watershed. Journal of Hydrodynamics Ser A, 164-174.in Chinese.

Tayfur, G., 2001. Modeling two-dimensional erosion process over infiltration surfaces. Journal of Hydrologic Engineering 6 (3), $259-262$

Tayfur, G., Kavvas, M.L., 1994. Spatially averaged conservation equations for interacting rill-interrill area overland flows. Journal of Hydraulic Engineering 120 (12), 1426-1448.

Tayfur, G., Kavvas, M.L., 1998. Areally-averaged overland flow equations at hillslope scale. Hydrological Sciences 43 (3), $361-378$.

Tayfur, G., Kavvas, M.L., Govindaraju, R.S., Storm, D.E., 1993. Applicability of St Venant equations for two-dimensional overland flows over rough infiltration surfaces. Journal of Hydraulic Engineering 119 (1), 51-63.

Woolhiser, D.A., Ligget, J.A., 1967. Unsteady, one dimensional flow over a plane-The rising hydrograph. Water Resources Research 3 (3), 753-771. 